\title{
In situ immunohistochemical analysis of cell adhesion molecules on human corneal endothelial cells
}

\author{
Beatrijs J J Foets, Joost J van den Oord, Riccardo Volpes, Luc Missotten
}

\begin{abstract}
Interaction of leucocytes with human corneal endothelial cells (HCECs) can be observed in several clinicopathological conditions, such as uveitis, keratitis, and corneal graft rejection. Since leucocyte-endothelial cell interactions involve various adhesion receptors we have analysed the expression and distribution pattern of the neural cell adhesion molecule (NCAM), the intercellular adhesion molecule-1 (ICAM-1), the vascular cell adhesion molecule-1 (VCAM-1), the endothelial leucocyte adhesion molecule-1 (ELAM-1), and the cluster of differentiation antigen-44 (CD44) on flat preparations of normal and organ-cultured HCECs. NCAM and ICAM were constitutively expressed on HCECs whereas VCAM-1, ELAM-1, and CD44 were absent from normal HCECs. However flat mounts of HCECs from organ-culture preserved corneas showed a mosaic-like distribution pattern of VCAM-1 and ELAM-1 positive cells and garland-like clusters of CD44 positive cells. We suggest that modulation of ELAM-1, VCAM-1, and CD44 expression on HCECs may contribute to the regulation of leucocytes-HCECs interaction in the case of anterior segment inflammation.
\end{abstract}

In a variety of ocular clinicopathological conditions interactions of human corneal endothelial cells (HCECs) with leucocytes can be observed with the slit-lamp. Clusters of inflammatory cells deposited on the inner surface of the cornea from the aqueous humour and known as keratic precipitates are seen in conditions of anterior segment inflammation - that is, keratitis and/or anterior uveitis. ${ }^{1}$ In particular T lymphocytes are thought to play a crucial role in mediating the local reaction against the corneal endothelium in corneal allograft rejection. ${ }^{234}$ Clinically endothelial immunoreaction is characterised by diffusely spread keratic precipitates or by a Khodadoust line migrating over the graft endothelium. ${ }^{56}$

In the past few years cell adhesion molecules which mediate interaction between leucocytes and various target cells have been extensively investigated. ${ }^{7-13}$ In addition to the intercellular adhesion molecule-1 (ICAM-1) ${ }^{14}$ is two other vascular cell adhesion molecules involved in leucocyte trafficking have recently been described - that is, the endothelial-leucocyte adhesion molecule-1 (ELAM-1), ${ }^{16} 17$ and the vascular cell adhesion molecule-1 (VCAM-1). ${ }^{18}$ The cluster of differentiation antigen-44 (CD44)

involved in lymphocyte recognition of high endothelial venules probably represents a novel type of cell adhesion molecule mediating cell-cell or cell-matrix interaction in multiple tissues. ${ }^{19} \mathrm{In}$ spite of these recent advances in basic immunology the mechanisms which regulate interactions between leucocytes and HCECs during anterior segment inflammation are virtually unknown.

We therefore wanted to identify cell adhesion molecules which might be involved in leucocytes-HCECs interactions; for this purpose we used in situ immunoperoxidase staining techniques and a panel of monoclonal antibodies to determine the expression and distribution of various adhesion molecules on flat mounts of HCECs. We chose to use flat mounts of HCECDescemet's membrane complexes to overcome the damage to and loss of HCECs in frozen tissue sections and because this method has previously shown heterogeneity among HCECs. ${ }^{2021}$

\section{Material and methods}

We studied the endothelium of seven corneoscleral rims (specimens 1-7), obtained following trephination of donor corneas at the time of keratoplasty. These donor corneas were derived from the Leuven Eye Bank. ${ }^{22}$ The corneas were excised 9-22 $\mathrm{h}$ post mortem from human cadaver eyes (age 47-79, mean 67) and were stored for various intervals (8-26 days, mean 18 days) in Minimum Essential Medium (Gibco, Paisley, Scotland) supplemented with $10 \%$ fetal calf serum (Gibco), $50 \mathrm{U} / \mathrm{ml}$ nystatin, $0.1 \mathrm{mg} / \mathrm{ml}$ amikacin, and $0.5 \mathrm{mg} / \mathrm{ml}$ ticarcillin at $32^{\circ} \mathrm{C}$. The viability of the corneal endothelial cell layer was evaluated by vital staining with Evans' blue.

Each corneal specimen was cut into several pieces and Descemet's membrane with the covering endothelial cell layer was gently stripped off from the underlying stroma using fine monofilament forceps. ${ }^{23}$ The samples of Descemet's membrane-endothelium complex were mounted on albumin-coated slides, dried overnight at room temperature, and fixed for $\mathbf{1 0}$ minutes in absolute acetone.

To study the effect of organ culture medium the endothelium of four human cadaver corneas (specimens 8-11), which were not preserved in medium, was treated in the same way. Age of the donors was $77,67,67$, and 44 years and postmortem enucleation time was $6,9,16$, and 24 hours respectively.

One cornea (specimen 12) from an eye enucleated because of primary malignant melanoma of the choroid (the patient was 70 years old) was divided into three parts. The endothelium of one part was peeled off
Ophartment Hospital Sint-Rafaël

Kapucijnenvoer 33, B-3000 Leuven, Belgium.

Accepted for publication 22 August 1991 
immediately after enucleation. The remaining two pieces were put in organ culture medium respectively during 5 and 10 days before the endothelium was stipped off.

Finally two diseased corneal buttons (specimens 13 and 14) with centrally perforated ulcer obtained at keratoplasty were included in the study. The Descemet's membrane with remaining endothelial cells was peeled off from the diseased corneal stroma and handled in the same manner.

Adhesion molecules were demonstrated by an avidin-biotin-peroxidase complex (ABC) method. Slides mounted with Descemet's membrane-endothelium complex were incubated with mouse monoclonal antibody listed in Table I. The optimal dilution of each antibody was determined by titration experiments on positive controls. The secondary antibody consisted of biotinylated rabbit-antimouse Ig, and the third
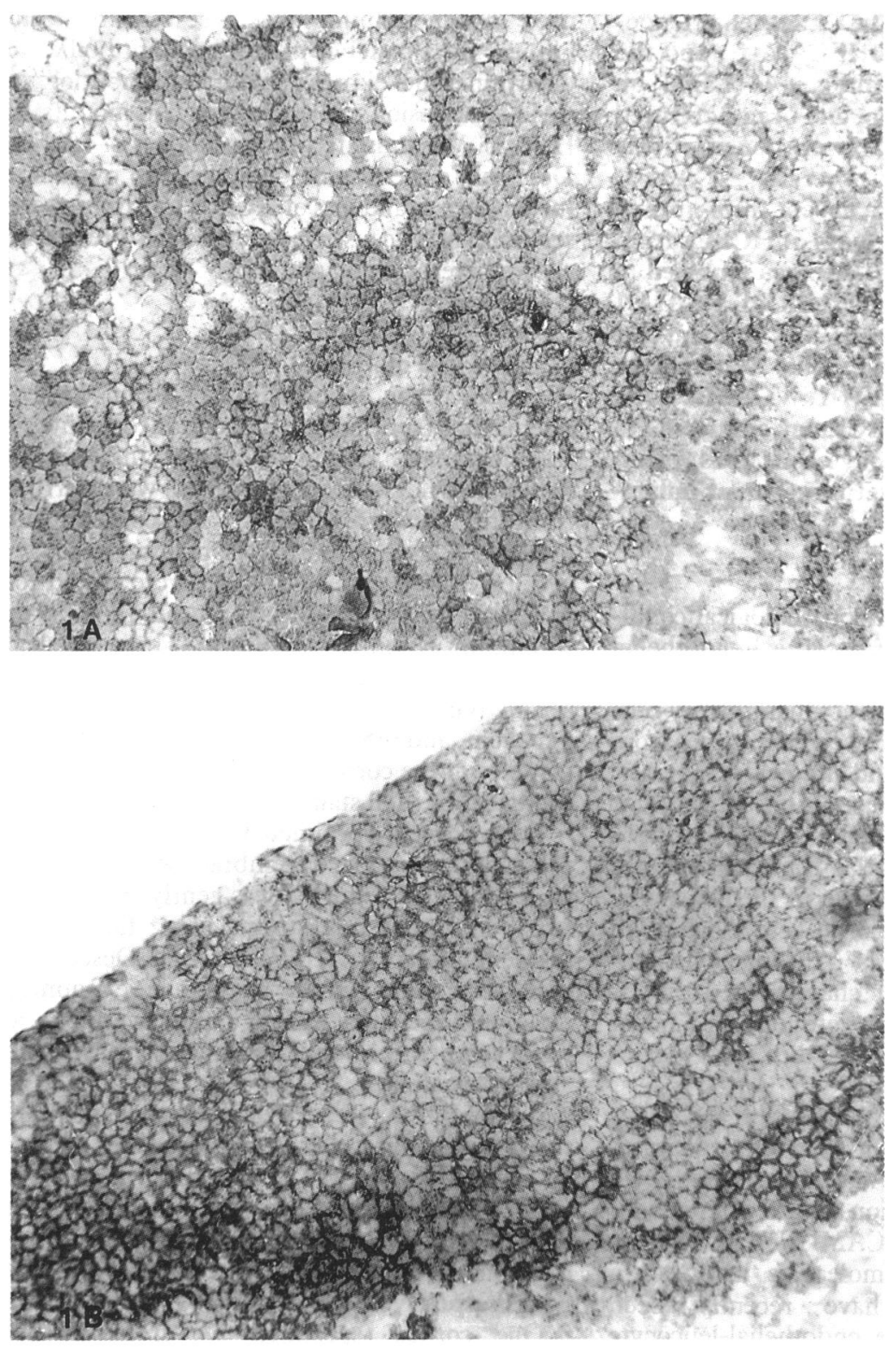

Figure 1 Staining of HCECs from organ culture preserved corneas with monoclonal antibodies against ICAM-1 (A), NCAM (B), VCAM-1 (C) and ELAM-1 (D). HCECs diffusely display immunoreactivity for ICAM-1 and NCAM. Expression of VCAM-1 and $E L A M-1$ is found on scattered endothelial cells of preserved corneas. Three-step indirect immunoperoxidase, counterstained with Harris' haematoxylin; original magnification: $\times 45$
Table 1 Monoclonal antibodies used in this study

\begin{tabular}{llll}
\hline Specificity (Refs) & Clone & $\begin{array}{l}\text { Working } \\
\text { dilution }\end{array}$ & Source \\
\hline ICAM-1 (24) & $84 \mathrm{H} 10$ & $1: 50$ & Serotec \\
NCAM (25) & Leu19 & $1: 160$ & Becton Dickinson \\
VCAM-1 (26) & 4B9 & $1: 10$ & Dr T Carlos \\
VCAM-1 (27) & E1/6 & $1: 10$ & Dr M P Bevilacqua \\
VCAM-1 (28) & 2 G7 & $1: 100$ & Dr W Newman \\
ELAM-1 (16) & H18/7 & $1: 250$ & Dr M Gimbrone \\
ELAM-1 (16) & H4/18 & $1: 250$ & Dr M Gimbrone \\
CD44 (29) & F10-44-2 & $1: 100$ & Dr R Dalchau \\
CD44(30) & NIH44-1 & $1: 1000$ & Dr Y Shimizu \\
CD44(12) & A3D8 & $1: 1000$ & Dr B F Haynes \\
CD44 (31) & Hermes-3 & $1: 500$ & Dr S Jalkanen \\
\hline
\end{tabular}

Table 2 Expression of adhesion molecules of flat mounts of HCECs

\begin{tabular}{llll}
\hline & Fresh cornea & $\begin{array}{l}\text { Organ culture } \\
\text { preserved cornea }\end{array}$ & Inflamed cornea \\
\hline ICAM-1 & diffusely+ & diffusely+ & diffusely+ \\
NCAM & diffusely+ & diffusely+ & diffusely+ \\
VCAM-1 & - & scattered+ & scattered + \\
ELAM-1 & - & $\begin{array}{l}\text { scattered+ } \\
\text { garland-like } \\
\text { CD44 }\end{array}$ & not demonstrated \\
& & diffusely+ \\
\hline
\end{tabular}

step consisted of the avidin-biotin-peroxidase complex. All incubations were carried out at room temperature for 30 minutes, and followed by a 15-minute wash in three changes of phosphate-buffered saline (PBS), $\mathrm{pH} 7 \cdot 2$. Peroxidase activity was developed with the use of 3-amino-9ethylcarbazole and $\mathrm{H}_{2} \mathrm{O}_{2}$ resulting in a brightly red colour of immunoreactive sites. After a final wash in PBS, pH $7 \cdot 2$, the sections were slightly counterstained with Harris' haematoxylin. Controls consisted of replacement of the primary monoclonal antibody by an irrelevant antibody of similar isotype or by PBS, $\mathrm{pH} 7 \cdot 2$. These controls were invariably negative.

\section{Results}

The distribution of NCAM, ICAM-1, VCAM-1, ELAM-1, and CD44 on HCECs of fresh, organ culture preserved and diseased corneas is summarised in Table 2.

ICAM-1 and NCAM were diffusely expressed on all HCECs of organ culture preserved and fresh corneas (Figs $1 A$ and $B$ ).

Monoclonal antibodies 4B9, E1/6, and 2G7, all directed to VCAM-1, gave identical staining results. With the exception of one corneal specimen corneal endothelial cells from freshly prepared corneas (specimens 8-12) did not express VCAM-1. However HCECs from organ culture preserved corneas consistently showed variable numbers of VCAM-1 positive cells scattered between VCAM-1 negative endothelial cells (Fig 1C). This mosaic pattern was present both in the centre and periphery of the cornea, and there was no relationship between the number of positive cells and the incubation time in the culture medium.

Monoclonal antibodies $\mathrm{H} 18 / 7$ and $\mathrm{H} 4 / 18$ both detecting ELAM-1 yielded similar staining patterns. ELAM-1 could not be identified on a fresh corneal specimen but was expressed on scattered endothelial cells derived from two preserved corneal rims (Fig 1D).

All four anti-CD44 monoclonal antibodies (F10-44-2, NIH44-1, A3D8, and Hermes-3) 
gave similar staining results. The CD44 molecule could not be detected on fresh corneal endothelial cells (Fig 2A). Flat mounts of HCECs derived from organ culture preserved corneas on the other hand showed remarkable garland-like clusters of CD44 positive cells (Figs 2B and C).

The endothelial cells of the two diseased corneal buttons (specimens 13-14) were diffusely CD44 positive. On one of the diseased buttons VCAM-1 positive HCECs were present.

\section{Discussion}

In the present study we have analysed the expression and distribution pattern of the adhesion molecules NCAM, ICAM-1, VCAM-1, ELAM-1, and the lymphocyte homing-receptor CD44 using in situ immunohistochemical techniques on flat preparations of HCECs.

NCAM and ICAM-1 are both relatively well characterised members of the immunoglobulin gene superfamily of adhesion molecules. ${ }^{32}$ They are similar in overall structure since each is an integral membrane glycoprotein constructed
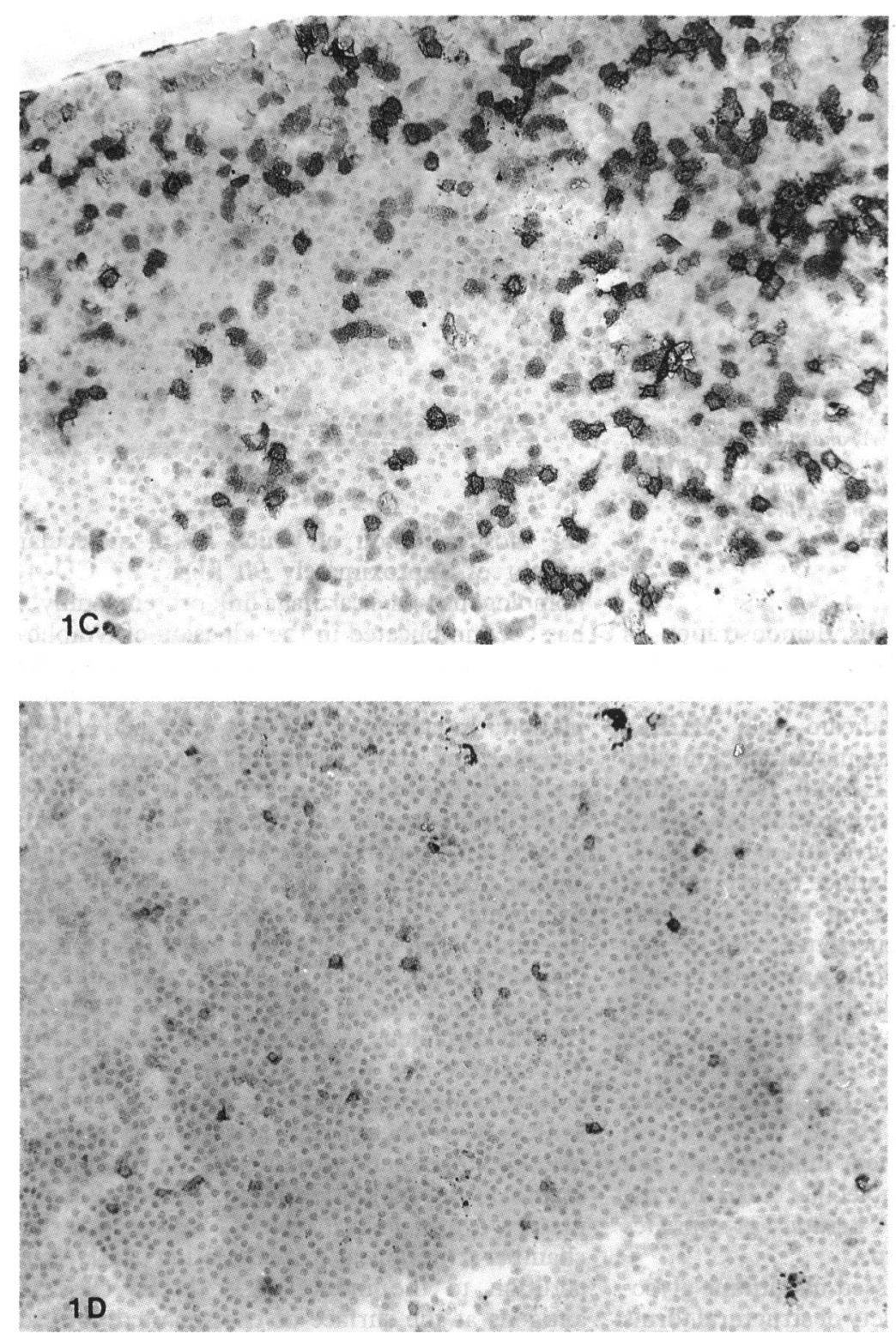

from five immunoglobulin-like domains forming the $\mathrm{N}$-terminal extracellular region.

NCAM mediates neuron-neuron and neuronmuscular adhesion through homophilic NCAMNCAM interactions. ${ }^{33}$ In addition NCAM has been shown to be involved in cell-matrix interactions. ${ }^{34}$ In adult life expression of NCAM is restricted to neural tissues and endocrine cells, ${ }^{33}{ }^{35}$ and the constitutive expression of NCAM by HCECs is in line with their neural crest origin. ${ }^{2036}$ Further studies will have to disclose whether NCAM serves in the adhesion of HCECs to each other or in the adhesion of these cells to matrix components of Descemet's membrane.

ICAM-1 is expressed on many cell types both of non-haematopoietic and haematopoietic lineage, ${ }^{14} 15$ and has been identified as a ligand for the LFA-1 molecule, ${ }^{37}{ }^{38}$ one of a trio of heterodimeric molecules known as the $\beta_{2}$ - or leucocyte - integrins present on virtually all leucocytes. ${ }^{11}$ In analogy with a recent report, ${ }^{39}$ HCECs were found to express ICAM-1 constitutively. Thus HCECs can serve as a cell type with which lymphocytes in the anterior eye chamber can interact via the ICAM-1/LFA-1 adhesion pathway a feature that has been proved recently by a leucocyte adherence assay using cultured HCECs. ${ }^{39}$

Recently two inducible vascular adhesion molecules have been identified - VCAM-1 and ELAM-1. VCAM-1 also belongs to the immunoglobulin gene superfamily of adhesion molecules and is induced by the cytokines IL 1 and TNF- $\alpha$ on the surface of vascular endothelial cells. ${ }^{18} 27$ VLA-4 a member of the $\beta_{1}$-integrin subfamily and primarily expressed on lymphocytes and monocytes ${ }^{40}$ has recently been shown to be the major ligand for VCAM-1.41 ELAM-1 is a member of a new family of adhesion proteins called selectins. ${ }^{78}$ These adhesion proteins have lectin-like domains on their outermost end suggesting that they recognise and bind to carbohydrates. ELAM-1 appears on the endothelium of blood vessels that have been stimulated by inflammatory cytokines and attracts neutrophils to inflamed areas. ${ }^{16} 1742$

VCAM-1 and ELAM-1 are absent from normal corneal endothelial cells. Unexpectedly however a mosaic-like expression of both vascular cell adhesion proteins was observed on flat preparations of HCECs from organ culture preserved corneas indicating induction of these molecules by a hitherto unknown component in the medium. Negative control experiments excluded the possibility that this patchy distribution was due to passive uptake of the antibody by necrotic HCECs. The observed heterogeneous expression of VCAM-1 and ELAM-1 on HCECs triggered by components in the culture medium adds to our previous demonstration of phenotypic heterogeneity among HCECs with regard to their intermediate filament make-up, ${ }^{20}$ their affinity for the lectin Ulex Europaeus Agglutinin $\mathrm{I}^{43}$ and their expression of MHC class II antigens in response to cytokines. ${ }^{21}$ The presence of VCAM-1 and ELAM-1 on a subset of HCECs does not necessarily indicate their vascular endothelial nature; the recent demonstration of VCAM-1 staining of inflamed mesothelium, ${ }^{+1}$ 



Figure 2 CD44 antigen expression on HCECs of a fresh cornea $(A)$ and of an organ culture preserved cornea ( $B$ and $C)$ No CD44 immunoreactivity is present on fresh HCECs. Garlandlike clusters of CD44 positive HCECs are seen on flat mounts of HCECs from organ culture preserved corneas. Three-step indirect immunoperoxidase, counterstained with Harris' haematoxylin; original magnification: $\times 45(A$ and $B)$, and $\times 36(C)$.

together with the previous demonstration of cytokeratin filaments in HCECs,,$^{20}$ would rather support their mesothelial nature.

The present data indicate that HCECs can express the cytokine-inducible adhesion molecules VCAM-1 and ELAM-1. It is therefore conceivable that inflammatory cytokines, which undoubtedly circulate in vivo during an inflammatory reaction, may induce expression of ELAM-1 and/or VCAM-1 on HCECs thereby promoting adherence of leucocytes to the corneal endothelium. This needs to be proved by in vitro studies adding various cytokines to the culture medium of the corneas as well as by monoclonal antibody blocking studies. It is tempting to speculate that the observed patchy distribution of adhesion molecules on HCECs occurs also in vivo during anterior segment inflammation and that this represent the molecular basis for the spotty configuration of keratic precipitates observed with the slit-lamp.

CD44 is a widely expressed membrane glycoprotein that exists in a variety of structural forms

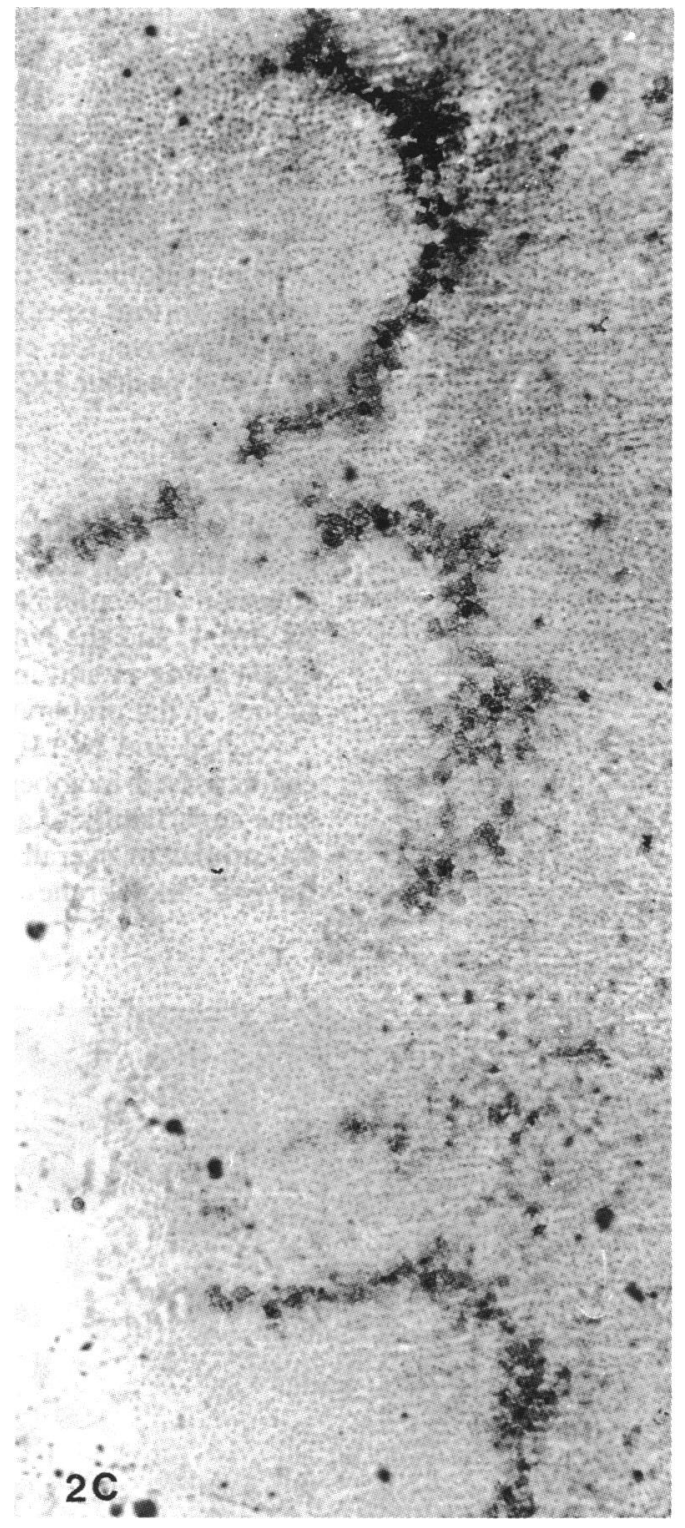

the most common of which has a molecular weight of approximately $90 \mathrm{kDa} .{ }^{194546} \mathrm{CD} 44$, homologous to the cartilage link protein family, ${ }^{47}$ has been implicated in the adhesion of lymphocytes to high endothelial venules and in the trafficking of leucocytes to sites of tissue inflammation; in addition CD44 would serve as a receptor for components of the extracellular matrix ${ }^{48}$ The wide distribution of the CD44 molecule on various cell types suggests that it is a general adhesion molecule mediating interaction among many cell types. CD44 is not expressed by normal HCECs but a peculiar garland-like distribution of CD44-positive cells was seen on flat preparations of HCECs from organ cultured corneas. In addition HCECs on the inflamed corneal specimens were diffusily CD44 positive. We suggest that CD44 represents an HCECinducible surface protein the expression of which confers new functional properties to HCECs in cases of inflammatory conditions. In the context of corneal transplantationimmunobiology inflammatory cytokines are released during anterior chamber irritation; the upregulation of CD44 in addition to the induction of MHC class II antigens at the surface of transplanted corneal 
endothelial cells may promote the afferent phase of the immune reaction via stimulation of $T$ helper cells. The peculiar distribution in garland-like sheets of CD44 positive cells may signify a hitherto unrecognised compartmentalisation of HCECs.

Dr M Gimbrone (Harvard Medical School, Boston, USA), Dr T Carlos (Harborview Medical Center, Seattle, USA), Dr M P Bevilacqua (Harvard Medical School, Boston, USA), Dr W Newman (Otsuka America Pharmaceutical, Rockville, USA), Dr R Dalchau (Blond McIndoe Center for Medical Research, East Grinstead, Dr Y Shimizu (National Institute of Health, Bethesda, Grinstead, Dr Y Shimizu (National Institute of Health, Bethesda, USA), Dr S Jalkanen (Turku University, Finland), Dr B F acknowledged for their generous gifts of monoclonal antibodies.

1 Nussenblatt RB, Palestine AG. Examination of ocular structures. In: Nussenblatt RB and Palestine AG, eds. Uveitis. Fundamentals and clinical practice. Chicago: Year Book Medical Publishers, 1989: 59-79.

2 Coster DJ. Mechanisms of corneal graft failure: the erosion of corneal privilege. Eye 1989; 2: 251-62.

3 Pepose JS, Nestor MS, Gardner KM, Foos RY, Pettit TH Composition of cellular infiltrates in rejected human corneal allografts. Graefes Arch Clin Exp Ophthalmol 1985; 222: 128-33.

4 Polack FM. Scanning electron microscopy of corneal graft rejection: epithelial rejection, endothelial rejection, and formation of posterior graft membranes. Invest Ophthalmol formation of poste

5 Casey TA, Mayer DJ. Rejection. In: Casey TA, ed. Corneal grafting. principles and practice. London: W B Saunders, grafting. principles

6 Hoffmann F, Pahlitzsch T. Predisposing factors in corneal graft rejection. Cormea 1989; 8: 215-9.

7 Springer TA. Adhesion receptors of the immune system. Nature 1990; 346: 425-34

8 Marx JL. New family of adhesion proteins discovered. Science 1990; 243: 1144

9 Carlos TM, Harlan JM.. Membrane proteins involved in phagocyte adherence to endothelium. Immunol Rev 1990 114: 5-28.

10 Duijvestijn A, Hamann A. Mechanisms and regulation of lymphocyte migration. Immunol Today 1989; 10: 23-8.

11 Kishimoto TK, Larson RS, Corbi AL, Dustin ML, Staunton DE, Springer TA. The leucocyte integrins. Adv Immunol DE, Springer TA.

12 Haynes BF, Hale LP, Denning SM, Le PT, Singer KH. The role of leucocyte adhesion molecules in cellular interactions: implications for the pathogenesis of inflammato

13 Hamann A, Thiele H-G. Molecules and regulation in lymphocyte migration. Immunol Rev 1989; 108: 19-44.

14 Rothlein R, Dustin ML, Marlin SD, Springer TA. A huma intercellular adhesion molecule (ICAM-1) distinct from LFA-1. F Immunol 1986; 137: $1270-4$

15 Staunton DE, Marlin SD, Stratowa C, Dustin ML, Springer TA. Primary structure of ICAM-1 demonstrates interaction between members of the immunoglobulin and integrin supergene families. Cell 1988; 52: 925-33.

16 Bevilacqua MP, Pober JS, Mendrick DL, Cotran RS, Gimbrone MA. Identification of an inducible endothelial-leucocyte adhesion molecule. Proc Natl Acad Sci USA 1987; 84: cyte adhesio

17 Hession C, Osborn L, Goff D, Chi-Rosso G, Vassallo C, Pasek $M$, et al. Endothelial leukocyte adhesion molecule 1: direct expression cloning and functional interactions. Proc Nat Acad Sci USA 1990; 87: 1673-7.

18 Osborn L, Hession C, Tizard R, Vassallo C, Lukowskyj S, Chi-Rosso G, et al. Direct expression cloning of vascular cell adhesion molecule 1, a cytokine-induced endothelial protein that binds to lymphocytes. Cell 1989; 59: 1203-11.

19 Picker LJ, Nakache M, Butcher EC. Monoclonal antibodies to human lymphocyte homing receptors define a novel class of adhesion molecules on diverse cell types. 7 Cell Biol 1989 109: 927-36.

20 Foets BJJ, van den Oord JJ, Desmet VJ, Missotten L. Cytoskeletal filament typing of human corneal endothelial cells. Cornea 1990; 9: 312-7.

21 Foets BJJ, van den Oord JJ, Billiau A, Van Damme J, Missotten L. Heterogeneous induction of MHC class II antigens on corneal endothelium by IFN- $\gamma$. Invest Ophthalmol Vis Sci 1991; 32: 341-5.

22 Pels E, Schuchard Y. Organ-culture preservation of human corneas. Doc Ophthalmol 1983; 56; 147-53.

23 Stocker FW, Eiring A, Georgiade R, Georgiade N. A tissue culture technique for growing corneal epithelial, stromal and endothelial tissues separately. Am $\mathcal{F}$ Ophthalmol 1958; 46 : 294-8.
24 Makgoba MW, Sanders ME, Luce GEC, Dustin ML, Springer TA, Clark EA, et al. ICAM-1 is a ligand for LFA-1dependent adhesion of B, T and myeloid cells. Nature 1988; 331: 86-8.

25 Lanier LL, Testi R, Bindl J, Philips JH. Identity of Leu19 (CD56) leucocyte differentiation antigen and neural cell adhesion molecule. F Exp Med 1989; 169: 2233-8.

26 Schwartz BR, Wayner EA, Carlos TM, Ochs HD, Harlan JM. Identification of surface proteins mediating adherence of CD11/CD18-deficient lymphoblastoid cells to cultured human endothelium. $\mathcal{F}$ Clin Invest 1990; 85: 2019-22.

27 Rice GE, Munro JM, Bevilacqua MP. Inducible cell adhesion molecule 110 (INCAM-110) is an endothelial receptor for lymphocytes. F Exp Med 1990; 171: 1369-74.

28 Graber N, Gopal TV, Wilson D, Beall LD, Polte T, Newman W. T-cells bind to cytokine-activated endothelial cells via a novel, inducible sialoglycoprotein and endothelial leukocyte novel, inducible sialoglycoprotein and endothelial le

29 Dalchau R, Kirkley J, Fabre JW. Monoclonal antibody to a human brain-granulocyte-T lymphocyte antigen probably homologous to the W $3 / 13$ antigen of the rat. Eur $\mathcal{F}$ Immunol 1980; 10: 745-9.

30 Shimizu Y, Van Seventer GA, Siraganian R, Wahl L, Shaw S. Dual role of the CD44 molecule in $T$ cell adhesion and activation. F Immunol 1989; 143: 2457-63.

31 Jalkanen S, Bargatze RF, de los Toyos J, Butcher EC. Lymphocyte recognition of high endothelium: antibodies to distinct epitopes of an 85-95 kD glycoprotein antigen differentially inhibit lymphocyte binding to lymph node, mucosal, or synovial endothelial cells. $\mathcal{F}$ Cell Biol 1987; 105: 983-90.

32 Williams AF, Barclay AN. The immunoglobulin superfamilydomains for cell surface recognition. Annu Rev Immunol 1988; 6: 381-405.

33 Rutishauser $U$. Developmental biology of a neural cell adhesion molecule. Nature $1984 ; 310: 549-54$.

34 Cole GJ, Glaser L. A heparin-binding domain from N-CAM is involved in neural cell-substrate adhesion. $f$ Cell Biol 1986; 102: 403-10

35 Langley OK, Aletsee-Ufrecht MC, Grant NJ, Gratzl M. Expression of the neural cell adhesion molecule NCAM in endocrine cells. $\mathcal{F}$ Histochem Cytochem 1989; 37: 781-91

36 Johnston MC, Noden DM, Hazelton RD, Coulombre JL, Coulombre AJ. Origins of avian ocular and periocular tissues. Exp Eye Res 1979; 29: 27-43.

37 Dustin ML, Rothlein R, Bhan AK, Dinarello CA, Springer TA. Induction by ILl and interferon- $\%$ : tissue distribution, biochemistry and function of a natural adherence molecule (ICAM-1). F Immunol 1986; 137: 245-54.

38 Marlin SD, Springer TA. Purified intercellular adhesion molecule-1 (ICAM-1) is a ligand for lymphocvte functionmolecule-1 (ICAM-1) is a ligand for lymphocyte func
associated antigen 1 (LFA-1). Cell 1987; 51: 813-9.

39 Elner VM, Elner SG, Pavilack MA, Todd RF, Yue BYJT, Huber AR. Intercellular adhesion molecule- 1 in human corneal endothelium. Am $\mathcal{F}$ Pathol 1991; 138: 525-36.

40 Hemler ME, Huang C, Takada Y, Schwarz L, Strominger JL, Clabby ML. Characterization of the cell surface heterodimer VLA-4 and related peptides. $\mathcal{F}$ Biol Chem 1987; 262: 1147885.

41 Elices MJ, Osborn L, Takada Y, Crouse C, Lukowskyj S Hemler ME, et al. VCAM-1 on activated endothelium interacts with the leucocyte integrin VLA-4 at a site distinc from the VLA-4/Fibronectin binding site. Cell 1990; 60 577-84.

42 Bevilacqua MP, Stengelin S, Gimbrone MA, Seed B. Endothelial leucocyte adhesion molecule-1: an inducible receptor for neutrophils related to complement regulatory proteins and lectins. Science 1989;243: 1160-72.

43 Foets BJJ, van den Oord JJ. Lectin binding to human corneal endothelium. Graefes Arch Clin Exp Ophthalmol 1991; 229: endoth

44 Rice GE, Munro JM, Corless C, Bevilacqua MP. Vascular and nonvascular expression of INCAM-110. A target for mononuclear leucocyte adhesion in normal and inflamed human tissues. Am $\mathcal{F}$ Pathol 1991; 138: 385-93.

45 Picker LJ, de los Toyos J, Telen MJ, Haynes BF, Butcher EC. Monoclonal antibodies against the CD44 $\operatorname{In}(\mathrm{Lu})$-related p 80, and Pgp-1 antigens in man recognise the hermes class of lymphocyte homing receptors. F Immunol 1989; 142: 2046-51.

46 Jalkanen S, Jalkanen M, Bargatze R, Tammi M, Butcher EC. Biochemical properties of glycoproteins involved in lymphocyte recognition of high endothelial venules in man. cyte recognition of high en

47 Goldstein LA, Zhou DFH, Picker LJ, Minty CN, Bargatze RF, Ding JF, et al. A human lymphocyte homing receptor, the hermes antigen, is related to cartilage proteoglycan core the hermes antigen, is related to cartilage

48 Carter WG, Wayner EA. Characterisation of the class III collagen receptor, a phosphorylated transmembrane glycoprotein expressed in nucleated human cells. $\mathcal{F}$ Biol Chem 1988; 263: 4193-201. 